\title{
ECONOMLA E SOCIEDADE: ÚLTIMOS ACHADOS SOBRE A "GRANDE OBRA" DE MAX WEBER
}

\section{Antônio Flávio Pierucci}

Habent sua fata libelli. [Os livros têm lá os seus fados.] Verso latino do século III.

\section{Economia e Sociedade ou $A$ ética protestante?}

Desde sua edição como obra póstuma em 1922, Economia e sociedade (ES) tem sido considerada a "obra principal", o magnum opus de Max Weber. A mais lida, porém, é A ética protestante e o "espirito" do capitalismo (EP). Evidente que entre o público de maior escolaridade, muitos dos que conhecem sua importância não se animam a lê-la por inteiro, apesar do tamanho "P" do seu texto principal. Dependendo da edição e da língua, não passa de cento e poucas páginas. ${ }^{1}$ No entanto, mesmo sem ser

Artigo recebido em julho/2008

Aprovado em agosto/2008 lida pela maior parte de quantos a sabem famosa e importante, mesmo assim a EP se mantém a mais lida das obras de Weber. No ano 2000, em listagens de livros que mostravam "os 10 mais lidos" do século XX, lá estava $A$ ética protestante, obra sempre muito bem colocada em ranques do gênero. Sua popularidade editorial é tamanha e tão estável, que mesmo na mente de um universitário que curse ciências sociais ela pode muito bem se representar como a obra "mais importante" do mais importante sociólogo alemão, mas na opinião da maioria dos sociólogos não é. Numa pesquisa de opinião feita em 1998 pela ISA, solicitando a seus membros que apontassem qual a obra de Sociologia mais importante e influente do século XX, Economia e sociedade saiu vencedora por ampla margem. ${ }^{2}$

No conjunto das obras de Weber, a EP é a mais conhecida, a mais gostosa de ler e, de longe, a mais bem acabada, sobretudo em sua segunda 
edição, revista e ampliada pelo autor em 19191920. ${ }^{3}$ Se, além do mais, aceitarmos o óbvio de que um livro só pode ser considerado lido quando lido por inteiro, mesmo no círculo menor dos especialistas em sociologia ou ciência política, direito ou economia, história ou filosofia, psicanálise ou psicologia, ou seja, entre os diplomados nas áreas de humanidades, também nesse público específico a mais lida das obras de Weber é a EP.

Já de saída a EP se mostrou dotada do condão de chamar a atenção e provocar polêmica. Desinteligências mil acerca do seu acerto. Controvertida "pela própria natureza", permanece objeto de críticas e anticríticas até agora, o que retroalimenta o vigor da celebridade de que goza entre o público intelectualizado. Pessoalmente considero a EP uma obra-prima - ein Meisterwerk -, mas nem por isso vou sair por aí dizendo que ela é "a obra principal" [das Hauptwerk] de Weber. Obra-prima eu sei que ela é, mas se é "a obra principal" de Weber, disso não tenho certeza e me pergunto por quê. Talvez porque seja mais fácil sentir o que seja uma obraprima do que ranquear uma obra principal.

Seja como for, o interesse aqui é contar, simplesmente contar, como foi o processo de formação-edição de Economia e sociedade.

\section{Trajetória editorial \\ de Economia e sociedade}

Max Weber morreu em junho de 1920 aos 56 anos de idade. No ano seguinte à sua morte, em outubro de 1921, sua viúva já estava redigindo o prefácio à primeira edição de Economia e sociedade calhamaço de um volume só que ela acabara de organizar $^{4}$ e que sairia no ano seguinte com o longo título Grundriss der Sozialökonomik. III Abteilung. Wirtschaft und Gesellschaft (Elementos de economia social. Seção III. Economia e sociedade). Num texto de poucas linhas ela dizia, com a maior naturalidade do mundo como se estivesse falando que o céu é azul, que aquela era a "obra principal do autor": "dieses nachgelassenen Hauptwerkes des Verfassers" (WuG, p. xxxii; EeS I:, p. xxxix). Obra principal ainda que póstuma.

Em uma única enunciação - "esta obra principal póstuma" - Marianne Weber transferia a um juízo interpretativo seu, inteiramente subjetivo, acerca da "principalidade" de ES no conjunto da obra "do autor", o mesmo teor de facticidade objetiva pertencente ao fato de ser publicação póstuma. Quem de nós, desde os tempos de estudante de Ciências Sociais ou coisa parecida, não terá lido um comentarista ou escutado um professor ensinando justamente isto, que a obra principal de Weber é Economia e sociedade? E quantas vezes... A meu ver isso se explica pela razão, entre outras, de que já na primeira edição, por força do conciso atestado de distinção suprema emitido por Frau Weber naquele primeiro prefácio, $E S$ passou a ser automaticamente recebida como a "obra principal" de Weber. E tudo o que Marianne escreveu ali foi simplesmente isto: "A publicação desta obra principal póstuma do autor [dieses nachgelassenen Hauptwerkes des Verfassers] apresentou naturalmente muitas dificuldades" (WuG, p. xxxii; EeS I, p. xxxix).

Com a mesma naturalidade que Marianne incutiu à sua frase aparentemente despretensiosa, aos leitores sempre pareceu óbvio que fosse aquilo mesmo. Soava de tal forma natural, que ninguém duvidou disso até o dia em que, no ano de 1975, meio século depois de publicado o prefácio de Marianne Weber, apareceu na revista Kölner Zeitschrift für Soziologie und Sozialpsychologie um artigo para lá de corajoso e muito bem fundamentado, faiscante ao mesmo tempo que judicioso, precipitando nos arraiais weberianos uma espécie de ebulição prenunciada. O nome do artigo - "Das Werk Max Webers" ["A obra de Max Weber"] - não soava nada modesto, e nem podia, assinado que era pelo grande especialista não só nos escritos, mas também na escrita de Weber, Friedrich Tenbruck (1975), que, sendo quem era, um acadêmico de alto coturno e respeito intelectual, com sua acreditada voz discordante introduzia salgadíssima azeitona naquela empada consensual cinco décadas amanhecida, dizendo simplesmente algo como Será que ES é mesmo a obra principal de Weber? Assim é se lhe parece, só que a coisa não é assim tão garantida como parece. "O que significa obra principal?", perguntava o artigo, "O que é uma obra principal?".

Talvez esse termo ambíguo haja prejudicado a tal ponto a interpretação, que um olhar imparcial sobre as obras [de Weber] é quase impossível de conseguir. É tempo de retornar às fontes e ler os textos com honestidade, na esperança de que isso possa lançar nova luz sobre cada obra individualmente e sobre sua colocação no conjunto da obra (Tenbruck, 1975, p. 679). 
Dois anos depois, em 1977, Tenbruck (1977, pp. $715 \mathrm{ss}$ ) voltaria à carga em outro artigo, que no título já vinha vestido para matar: "Abschied von "Wirtschaft und Gesellschaft" ["Adeus a "Economia e sociedade"']. A extrema franqueza ostentada num título que ecoava outras tantas despedidas que os intelectuais estavam sendo obrigados a encarar nas últimas décadas do século XX funcionou como sinalização clara, inédita mas bem-vinda, de que estava irremediavelmente aberta a discussão dos inconvenientes intelectuais de uma tradição como aquela, acriticamente apoiada na vigência inercial de uma "idéia recebida" acerca do valor (tido por) inconteste de uma obra individual no conjunto da obra de um autor que se mostrou prolífico até depois de morto.

De fato. Por morrer prematuramente Weber deixou, sem publicar, um vasto material escrito resultante de suas batalhas intelectuais em vários frontes. A esse material inédito seus biógrafos, comentaristas e editores afixaram a designação Nachlass [espólio]. ${ }^{5}$ Uma quantidade enorme e desordenada de textos entre datilografados e manuscritos, alguns dos quais já no processo de revisão para publicação, outros apenas esboçados, outros semiprontos à espera de tempo disponível para serem reformatados ou reformados ou mesmo reescritos. Alguns deles já postos de lado, superados conceitualmente pelo avanço teórico do autor. Sua viúva Marianne, enquanto viveu, fez bom proveito desse Nachlass, comenta Klaus Lichtblau (2003, p. 233), seja como biógrafa do marido, seja como organizadora editorial de seus escritos póstumos, sem jamais perder a chance, claro, de emitir sua respeitada opinião de intelectual, intelectual que era, a propósito dessa ou daquela obra individual, conforme exemplificado no prefácio à primeira edição de $E S$ há pouco citado.

Depois dos retumbantes artigos de Friedrich Tenbruck nos anos de 1970, demorou um pouco para que outro perito alemão em estudos weberianos saísse a campo atirando na mesma direção, mas isso devia ocorrer mais cedo ou mais tarde. Foi já no bojo da formidável empreitada editorial de confecção da edição completa dos escritos de Weber Max Weber-Gesamtausgabe (MWG), iniciada nos anos de 1980 - que a certa altura dos trabalhos se fez ouvir a voz autorizada de Wolfgang Schluchter, participante ativo na direção do projeto. Com vistas a subsidiar o preparo da nova edição crítica de
Economia e sociedade, Schluchter fez circular em 19851986 um paper cujo título punha na mesa, de uma vez só, um par de coisas nada fáceis de dizer: que existia um mito chamado Economia e sociedade, e que esse mito estava chegando ao fim. Título do artigo: "Wirtschaft und Gesellschaft: Das Ende eines Mythos" ["Economia e sociedade: o fim de um mito"]. ${ }^{7}$ E portanto, o fim de uma era de meio século em que ES manteve a reputação de ser a obra de Weber mais decisiva para a formação, o desenvolvimento e a consolidação de um status de ciência específico da Sociologia. Obra, portanto, fun-da-men-tal. Que ainda hoje é amplamente recomendada como a mais relevante para análises sociológicas que queiram dar conta, sem reducionismos nem soluções fáceis, da multimodal concatenação "agente-estrutura" na fase tardia do capitalismo.

Quando veio a público em 1922, com um texto derramado e de estilo irregular, alguns capítulos inacabados e um título abstrato e bifronte, esse extenso tratado de Sociologia explícita - "minha Sociologia" [G1], Weber passou a identificá-lo na correspondência que manteve com seu editor $\mathrm{e}$ amigo Paul Siebeck no ano de 1913 (cf. Mommsen, 2000, notas 32 a 35) - chegava com a promessa, assim presumiu Marianne, de conjuminar Sociologia sistemática cum Sociologia histórica. Aos olhos dela, que a montou, ES era uma obra unitária composta de duas partes, "uma Primeira Parte de 'Sociologia abstrata' e uma Segunda Parte de 'Sociologia concreta"' (EeS I, p. xxxix). Resultado do trabalho exaustivo de muitos anos de seu prolífico autor, sem calcular todo o tempo que ela reverentemente acabara de lhe devotar.

As duas primeiras edições alemãs de $E S$, a de 1922 em volume único, e a de 1925, revista e repartida em dois volumes, aconteceram sob o comando de Marianne Weber. A terceira edição, de 1947, também é dela, posto que reimpressão da segunda, portanto inalterada. ${ }^{9}$

Marianne morreu em 1954. Dois anos depois saía a quarta edição de $E S$, apresentando-se na capa como "nova". Organizada por Johannes Winckelmann, ${ }^{10}$ trazia mudanças significativas resultantes das intervenções mais ousadas do novo organizador e primeiro promoter, como logo se perceberá - na composição e organização do texto. A modificação mais visível: no enunciado do título. Em vez do velho título principal Grundriss der Sozialökonomik [Elementos de economia social que se fazia seguir do 
subtítulo III Abteilung. Wirtschaft und Gesellschaft. [Seção III: Economia e sociedade], o livro surgia agora com o título principal trocado para Wirtschaft und Gesellschaft [Economia e sociedade] e, surpresa maior, com um subtítulo inédito: Grundriss der verstehenden Soziologie [Elementos da sociologia compreensiva], verdadeiro ato consumado de entronização do sintagma "Sociologia compreensiva" como parte integrante do título completo da reverenciada "obra principal" de Weber.

No prefácio que escreveu para a quarta edição alemã de $1956^{11}$ o novo organizador Johannes Winckelmann explica circunstanciadamente as mudanças que decidira fazer tanto no formato da obra como em seu elenco de matérias. Não é este o lugar para examinar essa peça, que continua a ser de leitura indispensável aos que se interessam pela obra de Weber. Em tempo: o formato assumido por ES na quarta edição tornou-se referência para as traduções e reedições feitas a partir de 1956. A versão brasileira, de 1991, é tradução da quinta edição, de 1972, também organizada por Winckelmann, que fez um novo prefácio, ainda mais minucioso em esclarecimentos e argumentadas justificativas. Ao escrever seus dois prefácios, Winckelmann fez questão de pontuá-los com a mesma distinção cravada por Marianne no prefácio de 1921 - Hauptwerk, obra principal. Tome-se o prefácio à quarta edição. Veja-se a primeira frase e, em seguida, a última. Exatamente nas duas extremidades de sua apresentação, simetria essa que só pode ter sido intencional, o organizador saúda ES com o status de obra principal:

[Primeira frase]: A obra principal de Max Weber, obra póstuma, apresenta-se aqui de forma modificada e desprendida do contexto da obra coletiva Grundriss der Sozialökonomik $(G d S)$, da qual constituía até agora a seção III (EeS I, p. xxxi).

[Última frase]: Então teria sido alcançado o objetivo que orientou o organizador do texto: abrir a uma compreensão ampliada a obra principal de Max Weber mediante a maior facilidade de leitura e o acesso mais fácil a seu curso de pensamento - em benefício da pesquisa, do ensino e da cultura intelectual (Idem).

Ao leitor atento, essa simetria nas duas pontas de um texto cujo miolo chega até ele amarrado pelo (hoje criticado) wishful thinking de fazer dele uma obra una, um todo coerente, é um indicador de que Winckelmann estava de fato disposto a avançar nessa direção, intervindo mais ativamente do que a viúva havia feito, assumindo mais à risca a idéia segundo a qual uma grande obra, para ser a principal, tem que ser una. Daí a repetição, em seus prefácios, do mantra acionado por Marianne, obra principal, obra principal. Mas não ficou só aí. Foi além. Cunhou seu próprio elogio. $\mathrm{E}$ foi assim que, além da insígnia de "obra principal" que recebera da primeira organizadora, ES receberia do segundo a medalha de "grande Sociologia": "Max Webers grosse Soziologie” (cf. $W u G$, p. xxv; EeS I, p. xxxi):

A primeira parte da grande Sociologia de Max Weber, que contém a teoria dos conceitos, foi escrita após a primeira Guerra Mundial, nos anos de 1918 a 1920.

[...] a contribuição de Max Weber que continha sua grande Sociologia para o conjunto do Grundriss der Sozialökonomik.

[...] Todos os esforços dedicados à estruturação e conformação do texto de Economia e Sociedade não podem desfazer o fato de que, ao morrer, Max Weber deixou sua grande Sociologia sem levá-la a cabo (pp. xxxi, xxxi, xxxvii).

Em 2000 a expressão voltou a circular. Foi no título de um dos últimos artigos de Wolfgang J. Mommsen (2000), artigo-referência para todos os que se interessam em saber do estado da arte das novas discussões acadêmicas em torno da confecção e da estruturação de $E S$, discussões que não param de recomeçar, suscitadas pelas constantes descobertas dos pesquisadores pari passu à progressão da garimpagem no espólio de Weber no contexto da $M W G$. No título desse artigo de Mommsen publicado em inglês no ano 2000, chama a atenção o aceno (irônico, parece-me) à apologia cunhada por Winckelmann.

É que o texto da "grande Sociologia" resulta de uma história editorial no mínimo irregular, para não dizer atabalhoada. Até a quinta edição, de 1972, cada edição decorria o mais das vezes de decisões quase inteiramente pessoais, tomadas sem maiores discussões mesmo em âmbito privado, que dirá públicas. Pouco ou nada discutidas na origem, com o correr do tempo as edições clássicas foram ficando cada vez mais discutíveis. Era inevitável.

Retomando. A primeira edição (1922), a cargo de Marianne Weber, resultou de várias conjeturas e algumas precipitações, mas raras intervenções diretas nos textos. Já para a segunda, de 1926, reimpressa em 1947, Marianne fez modificações formais apenas superficiais, tais como a divisão em dois volu- 
mes para facilitar o manuseio do leitor, e a juntada do ensaio de "Sociologia da música" à guisa de anexo. Quase nada diferentes uma da outra, padecem ambas da mesma suposição segundo a qual se trataria de uma obra una; fragmentária e incompleta, porém dotada de coerência entre as partes. As edições seguintes (1956 e 1972) ficaram a cargo de J. Winckelmann, muito mais afoito do que ela na estratégia editorial de transformar o texto lacunar e obviamente descontínuo numa obra unitária sem falhas evidentes de continuidade. Por isso talvez Winckelmann tenha entendido como dever seu apresentar ao público leitor um texto com muito menos vazios do que o das edições transadas por Marianne. Certo da validez dessa estratégia editorial, o novo organizador não hesitou em cobrir as lacunas com textos que ele mesmo compôs, recortando e co-lando trechos de outras obras de Weber, escritas com outros objetivos e outros dispositivos conceituais. ${ }^{12}$

Foi confusa mesmo a trajetória editorial de $E S$. Cheia de idas e vindas, de pega e larga, puxa e estica, recorta e cola. Muitas suposições enviesadas, hesitações várias e imprudências não raras. Alterações maiores ou menores a depender de acréscimos ou deslocamentos quando julgados cabíveis pelos curadores da obra (e da hora).

\section{História da redação \\ de Economia e sociedade}

Também a redação de ES teve que encarar uma trajetória cheia de obstáculos, turbulências, guinadas, interrupções, atrasos e prazos dilatados, desistências, recomeços, retomadas parciais novamente interrompidas. E, por fim, a morte prematura do autor. Do final do século passado para cá, foi justamente desta parte da "história da obra" seu processo de escrita - que ficamos sabendo muito mais coisas do que antes, e as vamos sabendo cada vez com mais detalhes. Escarafunchar uma Werkgeschichte [história da obra] é para isso mesmo, e é principalmente por isso que pensei em escrever este artigo, menos reflexivo ou interpretativo do que eu gostaria que fosse, apenas informativo. De qualquer modo, se me permitem os colegas, só quero aqui prestar serviço. Aos familiarizados com as questões que se levantam quando se ajusta mais o foco na obra de Weber, mas também àqueles que eventualmente quiserem se deixar levar pela curiosidade inespecífica por um primeiro encontro com os problemas de redimensionamento e reinterpretação que são recolocados a uma grande obra, seja ela qual for, pela descoberta de novas datas e datações em suas origens e formação.

Origens, vamos lá. A coisa começou em 1909. Com 44 anos, Weber participou em janeiro de 1909 da fundação da Sociedade Alemã de Sociologia [Deutsche Gesellschaft für Soziologie] em Berlim, elegendo-se membro da primeira diretoria ao lado de Ferdinand Tönnies, Georg Simmel, Heinrich Herkner e Werner Sombart. Segundo o biógrafo Dirk Käsler (1988, p. 15), foi nesse período que ele se definiu pela primeira vez como "sociólogo". Afastado das lides docentes havia seis anos, foi também no ano de 1909 que Weber achou de aceitar o convite de Paul Siebeck para assumir como editor principal um projeto editorial de grande envergadura e execução complexa.

A idéia que presidia ao projeto do editor Paul Siebeck era a de ocupar com algo similar, tão volumoso quanto, porém melhor e mais atual, o lugar ocupado desde 1882 pelo Handbuch der politischen Ökonomie [Manual de economia política], obra em cinco volumes muito usada para fins pedagógicos, porém bastante desgastada já. O nome inicialmente pensado para a nova coletânea era o mesmo da anterior, Handbuch derpolitischen Ökonomie, logo mudado para Grundriss der Sozialökonomik [Elementos de economia social por sugestão do próprio Weber. A ele caberia dirigir como editor principal a organização da nova coletânea, igualmente gigantesca, pensada para cinco volumes tal como a antiga, divididos em seções compostas de capítulos cada um redigido por um coautor escolhido a critério do editor principal. Weber ficaria com pelo menos um dos capítulos.

Quando Weber embarca na ousadia dessa aventura editorial, já estava pronto na editora um plano geral dos temas a abordar. O que ele faz? Espera alguns meses e, em maio de 1910, aparece com um plano inteiramente novo para a totalidade da coletânea (doravante referida aqui como Grundriss). Importante: o conteúdo desse primeiro sumário esboçado por Weber e denominado Stoffverteilungsplan Plano de distribuição das matérias] só foi divulgado recentemente, em 1986, no último livro escrito por Johannes Winckelmann (1986, pp. 150-155).

No primeiro sumário de Weber constava um título, "Wirtschaft und Gesellschaft" ["Economia e 
Sociedade"], por enquanto apenas como título de capítulo: o Capítulo IV da Seção III do Livro Primeiro, justamente aquele que o próprio Weber decidira que seria a sua contribuição para o Grundriss. Considero importante destacar aqui todos os lances relativos à questão do nome "Economia e sociedade", questão sobre a qual Gabriel Cohn, na apresentação da edição brasileira de EeS, escreveu o seguinte em 1991:

Uma única referência já poderá indicar quão vasta é a matéria para debate, no caso. É que seu próprio título está sujeito a dúvidas bastante plausíveis, que remetem à primeira das mencionadas dificuldades de tradução. Ocorre que o termo "sociedade" [Gesellschaft] não exprime conceito central na terminologia weberiana, na qual é substituído nos momentos decisivos por uma expressão que designa mais propriamente as relações interindividuais constitutivas da sociedade do que esta como rede de relações já dada (cf. EeS I, p. xiii).

Pessoalmente quero crer que as dúvidas que em 2008 ainda possam pairar sobre a justeza ou não, de índole teórica ou não, de cunho biográfico ou não, deste que se tornou por decisão de Winckelmann em 1956 o nome principal da "grande Sociologia" de Weber, elas não podem mais incidir, como antes incidiam, sobre a facticidade biográfica de sua autoria por Weber. O que não impede, longe disso, que a controvérsia possa e mereça prosseguir quando o que estiver em jogo for o significado genuinamente weberiano (e não mais a autoria efetivamente weberiana) de um título como esse, posto sob suspeita sempre que se focaliza o fato de seu enunciado, tal como está, aventar a relação entre duas entidades abstratas, expressas por dois termos tão sociologicamente gerais como "economia" e "sociedade". O fato novo trazido pelas descobertas feitas pela recente "arqueologia" das obras de Weber acionada no âmbito do megaprojeto $M W G$, encerra assim uma parte importante da discussão: a formulação duplamente abstrata do título do Capítulo IV da Seção III veio mesmo da pena de Weber. Ela consta do primeiro sumário que ele esboçou para o Grundriss em 1910.

E tem mais. Conforme se verá logo a seguir, a autoria do enunciado desse abstrato binômio é pelo menos duas vezes de Max Weber. De título de capítulo que havia sido no sumário de 1910, em 1914 passou a ser, com a anuência de Weber, o título de toda a Seção C do segundo sumário. Isso explica por que vai figurar postumamente na capa das edições organizadas por Marianne como título da Seção III, isto é, da contribuição assinada por Weber ao Grundriss der Sozialökonomik, designação esta que se preservou na capa como título principal (ver abaixo reprodução da capa). Somente na quarta edição de 1956 Economia e sociedade entrará como título principal da "obra principal" de Max Weber.

Passemos agora uma vista de olhos pelo sumário de 1910, parcialmente transcrito a seguir:

\section{Sumário de 1910}

Livro Primeiro. Economia e ciência econômica [Wirtschaft und Wirtschaftswissenschaft]

Seção III. Economia, natureza e sociedade [Wirtschaft, Natur und Gesellschaft]

[...]

Cap. $4^{\circ}$. Economia e sociedade [Wirtschaft und Gesellschaft] - Max Weber

a) Economia e direito [Wirtschaft und Recht]

1. Relação de princípio [prinzipielles Verbältnis]

2. Épocas no desenvolvimento da situação hodierna

[Epochen der Entwicklung des heutigen Zustands]

b) A economia e os grupos sociais: grupo familiar e comuna; estamentos e classes; Estado [Wirtschaft und soziale Gruppen: Familien- und Gemeindeverband; Stände und Klassen; Staat

c) Economia e cultura (crítica do materialismo histórico) [Wirtschaft und Kultur (Kritik des historisches Materialismus)]

Dá para ver claramente que o primeiro sumário tem dicção econômica. Não esquecer, a propósito, que o nome escolhido para a coletânea propunha precisamente ensinar "Elementos de Economia Social". No esquema que concebeu, Weber parece querer frisar em grossas pinceladas que a proposta era mesmo a de mostrar com quantas relações não-econômicas se faz uma "economia social". Não haverá de ser por nada que o conteúdo alocado sob o intertítulo "Economia e sociedade" aparece dividido em três grandes conjuntos temáticos pondo em relação a economia com outras ordens de vida não-econômicas: a) Economia e direito; b) Economia e os grupos sociais; c) Economia e cultura.

Ocorre que o início da publicação do Grundriss acabou sendo adiado, e isso aconteceria mais de uma vez devido a uma série de circunstâncias: atrasos crônicos na confecção dos textos (inclusive da parte de Weber), expansão do conteúdo de algumas contribuições (incluídas aí as do próprio Weber) etc. 
A confecção da grande coletânea com base no primeiro esquema ia ficando cada vez mais problemática. Diante de tantos e repetidos atrasos, ao invés de desistir do Grundriss de uma vez, Weber e o editor Siebeck depois de algum tempo concordaram em partir para um novo plano geral de conteúdos.

Em março de 1914 Siebeck apresentou-lhe um novo sumário com a distribuição de temas e autores. Para fins de comparação imediata, ainda que não sinóptica, confira-se abaixo o novo sumário de 1914 com as especificações temáticas da Seção $\mathrm{C}$, a qual, como se sabe, tocava a Weber redigir:

Sumário de 1914

Seção C: Economia e Sociedade [Wirtschaft und Gesellschaft]

I. A economia e as ordens e poderes sociais [Die Wirtschaft und die gesellschaftlichen Ordnungen und Mächte] - Max Weber

1. Categorias das ordens sociais [Kategorien der gesellschaftlichen Ordnungen] - Economia e direito em sua relação de princípio [Wirtschaft und Recht in ibrer prinzipiellen Beziehung] - Relações econômicas dos agrupamentos em geral [Wirtschaftlichen Beziebungen der Verbände im allgemeinen]

2. Comunidade doméstica, oikos e empresa [Hausgemeinschaft, Oikos und Betrieb]

3. Associação de vizinhança, clã, comunidade local [Nachbarschaftsverband, Sippe, Gemeinde]

4. Relações comunitárias étnicas [Ethnische Gemeinschaftsbeziehungen]

5. Comunidades religiosas [Religiöse Gemeinschaften] Condicionantes de classe das religiões [Klassenbedingheit der Religionen ] - Grandes religiões e disposição econômica [Kulturreligionen und Wirtschaftsgesinnung]

6. A comunitarização de mercado [Die Marktvergemeinschaftung]

7. A associação política [Der politische Verband] - As condições do desenvolvimento do direito. Grupos de status, classes, partidos. A nação [Die Entwicklungsbedingungen des Rechts. Stände, Klassen, Parteien. Die Nation]

8. A dominação [Die Herrschaft -

(a) Os três tipos de dominação legítima [Die drei Typen der legitimen Herrschaft]

(b) Dominação política e hierocrática [Politische und bierokratische Herrschaft

(c) A dominação não-legítima: Tipologia das cidades [Die nichtlegitime Herrschaft: Typologie der Städte]

(d) O desenvolvimento do Estado moderno [Die Entwicklung des modernen Staates]

(e) Os partidos políticos modernos [Die modernen politischen Parteien]

(GdS I, pp. x-xi).

Visivelmente, o novo plano de trabalho proposto por Siebeck foi todo calcado nos conceitos que Weber desenvolvera durante os três anos anteriores. Evidência de que o período transcorrido entre 1910 e o final de 1913 representou na vida de Weber uma fase ultrafecunda de produção científica - sobretudo no tocante à elaboração de novos dispositivos conceituais, ${ }^{13}$ os quais, além de já se mostrarem afilados e apurados, parece que eram também convincentes, impressivos e virtualmente disseminantes. Tudo indica que Weber deve ter gostado muito do novo plano. Mexeu nele só um pouquinho, aqui e ali.

$\mathrm{E}$ já que o trabalho começou a engrenar e render, o lançamento de estréia da coletânea Grundriss pôde ser marcado para o verão de 1914, meados do ano. Foi quando veio à luz a edição do primeiro dos volumes previstos, ${ }^{14}$ finalmente.

Mas aí, em pleno verão, explodiu a guerra, a Grande Guerra. E não saiu nem sairia mais nenhum volume da coletânea. Em compensação, seu título Grundriss der Sozialökonomik ganharia anos depois inesperada sobrevida estampado como título principal da primeira edição, póstuma, da alegada "obra principal" de Weber. Para se constatar o status ainda relativamente secundário do título Economia e sociedade nas edições organizadas por Marianne, vale a pena conferir a capa da terceira edição, de 1947 (reimpressão da segunda, de 1925):

\author{
GRUNDRISS \\ DER \\ SOZIALÖKONOMIK \\ III. Abteilung \\ Wirtschaft und Gesellschaft \\ von \\ MAX WEBER
}

Dritte Auflage

Unveränderter Nachdruck der zweiten, vermerhrten Auflage

\section{TÜBINGEN 1947}

VERLAG VON J.B.C. MOHR (PAUL SIEBECK)

Chamo a atenção para o aporte de outra novidade importante no sumário de 1914. Logo abaixo do título da Seção C ("Economia e sociedade") aparece, assinalada pelo algarismo romano I, uma especificação de subtítulo, cuja designação se apre- 
senta em roupagem vocabular sociologicamente menos genérica do que o binômio de feitio abstrato que nomeia a Seção. O subtítulo de conteúdo sociológico mais explícito e específico diz: "A economia e as ordens e poderes sociais" ["Die Wirtschaft und die gesellschaftlichen Ordnungen und Mächte"]. Se bem o interpreto, eu o traduziria assim: "A economia em suas relações com as ordens societais e os poderes sociais". ${ }^{15}$ Deve ser por causa dessa sua formulação mais especificamente sociológica que, desde 1998, Wolfgang Schluchter (1998) passou a defender a proposta de que esse subtítulo entrasse na nova edição crítica de $E S$ no lugar do título agora tradicional.

Não custa lembrar, por fim, que nas edições correntes a que temos tido acesso em várias línguas, calcadas todas no padrão fixado por Winckelmann em 1956, a atual Segunda Parte de Economia e sociedade intitula-se "A economia e as ordens e poderes sociais" (EeS I, p. 207). Exceção notória é a edição norte-americana, de 1978, em que a Segunda Parte surge denominada de uma forma que eu diria instigantemente reelaborada: "The economy and the arena of normative and de facto powers" (cf. E\&S I, p. xi). Hoje, após a publicação do primeiro subvolume da nova versão de $E S$ na $M W G$, pode-se constatar que o enunciado presumidamente "mais weberiano" que Schluchter lançou como candidato a título geral da novíssima edição alemã não chegou lá. O comitê editorial mudou muita coisa na organização interna e na seqüência dos textos de $E S$, mas lhe manteve o nome usual (como adiante se verá no item 4 ).

Jean-Pierre Grossein é um dos novos nomes de peritos em Weber na França atual. Para ele, não resta dúvida de que o segundo sumário representa uma nítida inflexão teórica na busca de Weber por um teor sociológico mais intenso e mais consistente para o seu trabalho (Grossein, 2005, pp. 690ss). Aspecto que, segundo ele, aflora de modo ainda mais pronunciado quando o conteúdo do sumário de 1914 se deixa iluminar pelos termos da carta que Weber escreveu ao seu editor em 30 de dezembro de 1913, declarando nada menos do que isto:

[...] elaborei uma teoria e uma apresentação sociológicas que formam um todo abrangente e põem em relação todas as principais formas de comunidade com a economia: desde a família e a comunidade doméstica até a "empresa", o clã, a comunidade étnica, a religião (abrangendo todas as grandes religiões do mundo: uma
Sociologia das doutrinas de salvação e das várias éticas religiosas - semelhante ao que Troeltsch fez, só que desta vez para todas as religiões, e de forma bem mais concisa); por fim, uma teoria sociológica geral do Estado e da dominação. Estou no direito de afirmar que não existe ainda nada de equivalente, nem sequer algum "modelo" (Carta de Max Weber ao editor Paul Siebeck, 30.12.1913). ${ }^{16}$

O comentário que Schluchter faz do sumário de 1914 à luz dessa carta iluminadora focaliza aí a presença de um duplo interesse de conhecimento no Weber dessa fase mais intensamente sociológica: interesse pelas formas universais e pelas formas em desenvolvimento dos grupos sociais, o que converge para definir de modo mais assumido seu interesse maior pelo processo de racionalização da vida social, que envolve a "societarização" [Vergesellschaftung] das "relações comunitárias" [Gemeinschaftsbeziebungen] (cf. Schluchter, 1988).

Meses depois da carta de 30 de dezembro de 1913 que, hoje como nunca antes, impressiona a quantos descobrem seus termos, Weber escreveria novamente ao editor em 21 de abril de 1914, comunicando-lhe que seu texto para o Grundriss ainda iria demorar uns cinco meses para ficar pronto. "Meu manuscrito vai estar pronto em 15 de setembro, para podermos dar início à composição tipográfica." Quando sobreveio a Grande Guerra em agosto de 1914, era compreensível que o primeiro manuscrito, aí prometido para setembro, não estivesse pronto. O prazo não havia expirado ainda, mas...

O certo é que a coisa estacionou de vez. Durante a Guerra Mundial de 1914-1918, Weber parou de trabalhar em sua contribuição para o Grundriss. ${ }^{17}$ Só foi retomá-la em 1919 e, mesmo assim, recomeçando tudo surpreendentemente de um novo começo. Partiu para a composição de um texto puramente categorial de Sociologia, muito mais formal e sistemático do que histórico-substantivo, bem o contrário do que havia feito no primeiro manuscrito interrompido em 1914, considerado "mais sociológico". Ele parecia de tal modo decidido a uma reformulação radical do aparato conceitual que empregara nas etapas anteriores de sua produção, de tal forma determinado a colocar numa formulação rigorosamente sistemática um novo dispositivo de conceitos sociológicos, que, já no ano seguinte, estava pronto o novo trabalho. Foi ele mesmo que o entregou para impressão, chegando a corrigir-lhe as provas antes que 
uma morte prematura inesperadamente o apanhasse em junho de 1920.

A contribuição de Weber para o Grundriss tinha agora, na primavera de 1920, um conteúdo e uma forma totalmente outros, que não estavam previstos em nenhum dos planos editoriais anteriores. Agora já se tinha na gráfica um original pronto, de conteúdo novo, antes, novíssimo, cada capítulo centrado exclusivamente na definição e na explanação dos "conceitos sociológicos básicos" (Cap. I), das "categorias sociológicas básicas da atividade econômica" (Cap. II), dos "tipos de dominação" (Cap. III), dos "estamentos e classes" (Cap. IV). Em quatro capítulos, um verdadeiro tratado compacto de "Sociologia abstrata", teria comentado sua mulher.

Esse novíssimo trabalho de Sociologia sistemática, escrito em 1919-1920, será a Primeira Parte de Economia e sociedade nas edições póstumas que a viúva organizou e nas posteriores edições preparadas por Winckelmann. Para acompanhar essa "Primeira Parte", Marianne houve por bem juntar-lhe uma "Segunda Parte", que ela mesma terminou de montar reunindo os primeiros manuscritos redigidos pelo marido entre 1909 e 1914 e mais outros que lhe pareceram condizentes à contribuição de Weber ao projeto Grundriss. Um todo unitário em duas partes era a resultante que se pretendia. Para esse "todo em duas partes" manteve-se o título do Grundriss com a indicação explícita de que o conjunto constituía sua III Seção, chamada Economia e sociedade.

Foi assim que apareceu em 1922 a "primeira edição" de Wirtschaft und Gesellschaft. Comentário tranchã de Jean-Pierre Grossein:

Marianne fez a hipótese de que os manuscritos póstumos destinados ao Grundriss representavam análises sociológicas específicas que aplicavam - miraculosamente avant la lettre, eu acrescentaria - o aparato teórico elaborado por Weber em 1919-1920, ou seja, sua "Primeira Parte". J. Winckelmann, em suas edições de 1956 e 1972, [...] manteve o principal parti-pris editorial de Marianne. Acontece que essa hipótese estava errada: os dispositivos conceituais não são de modo algum os mesmos nas duas "partes" (Grossein, 2005, pp. 692-693).

Não há mais espaço para esticar essa discussão. Só cabe, no máximo, mais este comentário de Mommsen, que vale a pena ler, e é forte:

Para serem entendidas corretamente, as edições alemãs disponíveis, as duas de Marianne Weber e as duas de J. Winckelmann e também a edição inglesa organizada por Guenther Roth (que de certo modo é a melhor delas) têm que ser lidas de trás para frente, feito um livro chinês. Os quatro primeiros capítulos, que trazem os chamados "conceitos sociológicos básicos", foram escritos em 1919-1920 e entregues para publicação pelo próprio Weber pouco antes de sua morte prematura. Os outros segmentos, escritos na maior parte entre 1909 e 1914, foram publicados postumamente por Marianne Weber com base nos manuscritos que ela encontrou na escrivaninha dele. [...] É óbvio que Marianne Weber estava errada em sua suposição de que a antiga Seção chamada de Economia e Sociedade, que ela montou a partir dos textos de Weber, fosse parte integrante de um único projeto inclusivo (Mommsen, 2000, pp. 364-365).

\section{Novíssima edição alemã: o megaprojeto $M W G$}

Mommsen passou seus últimos anos de vida como membro da comissão de peritos responsável pela organização da nova edição completa dos escritos de Weber, o megaprojeto editorial denominado Max Weber-Gesamtausgabe (MWG) [Max Weber-Edição completa] (cf. Poggi, 1986). Junto com ele, participaram do primeiro comitê editorial desse ambicioso projeto ainda hoje in progress, figurões da academia alemã do porte de Wolfgang Schluchter, Horst Baier, M. Rainer Lepsius, Gangolf Hübinger e Johannes Winckelmann, este último também já falecido. Peritos em Weber todos eles.

Quando Mommsen publicou em 2000 o artigo supracitado em que aponta o "erro" de Marianne, havia terminado de organizar um dos subvolumes da nova edição crítica de Economia e sociedade, o subvolume 1, que sairia no ano seguinte como subdivisão do volume I/22 (ver listagem abaixo). Cumprira sua tarefa convencido de que a estratégia editorial principal adotada por Marianne Weber para as edições que ela organizou padecia de um "erro" estrutural e estruturante.

Para os que acompanham tanto a progressão regular da publicação de volumes produzidos no bojo dessa magnífica aventura editorial patrocinada pela Academia de Ciências da Baviera, como os debates públicos que costumam anteceder a cada novo lançamento, era de esperar que a nova edição de Economia e sociedade, prevista para começar a sair no ano 2000, incorporasse na organização da edição a única conclusão prática que se impunha sem discordâncias: corrigir o erro.

Dito e feito. Na atual edição crítica alemã, ES surge literalmente decomposta em dois volumes. 
Dois volumes não apenas separados $(M W G$ I/22 e I/23), mas também heterogêneos, destituídos da antiga "unidade ilusória" (Chazel, 2005, p. 642) e realinhados na ordem cronológica de redação dos originais. Inverte-se com isso aquele arranjo de "livro chinês" que lhe dera Marianne, inversão que Winckelmann só fez reproduzir. Da heterogeneidade de seus conteúdos e de suas datas, os subtítulos que se seguem dão conta ao grande título comum Wirtschaft und Gesellschaft. O volume I/22, que reúne os manuscritos redigidos entre 1909 e 1914, intitula-se Wirtschaft und Gesellschaft. Die Wirtschaft und die gesellschaftlichen Ordungen und Mächte. Nachlass [Economia e sociedade. A economia e as ordens e poderes sociais. Espólio]. O tomo I/23 chama-se Wirtschaft und Gesellschaft. Soziologie. Unvollendet 1919-1920 [Economia e sociedade. Sociologia. Inacabado 1919-1920]. Confira-se a lista dos volumes e subvolumes a seguir.

Volumes e subvolumes da $M W G$ contendo Economia e sociedade

Volume I/22: Wirtschaft und Gesellschaft. Die Wirtschaft und die gesellschaftlichen Ordnungen und Mächte. Nachlass [Economia e sociedade: a economia e as ordens e poderes sociais. Espólio]

Subvolume 1: Gemeinschaften [Comunidades] 2001 Subvolume 2: Religiöse Gemeinschaften [Comunidades religiosas] 2005

Subvolume 3: Recht [Direito] 2006

Subvolume 4: Herrschaft [Dominação] 2005

Subvolume 5: Die Stadt [A cidade] 2000

Subvolume 6: Materialien und Register [Materiais e anotações]

Volume I/23: Wirtschaft und Gesellschaft. Soziologie. Unvollendet 1919-1920 [Economia e sociedade. Sociologia. Inacabado 1919-1920]

Os organizadores da $M W G$, ao que parece, enfrentaram muita fadiga para deslindar tamanho cruzamento de quebra-cabeças. Os resultados a que chegaram nos textos já publicados de Economia e sociedade em nova edição alemã (começando em 2000 com o subvolume 5 sobre $A$ cidade) mostram que muitas das eternas questões relativas à obra de Weber ficam mais fáceis de responder satisfatoriamente quando se pode fazer com maior segurança documental uma análise da história dos seus textos, vale dizer, uma arqueologia de cada obra individualmente. $\mathrm{E}$ isso a $M W G$ vem tornando possível a cada novo lançamento.

\section{Notas}

1 Excluindo-se, claro, o aparato de notas de rodapé, que praticamente duplica o número de páginas do conteúdo principal.

2 Cf. Camic et al. (2005, pp. 1 e 24), onde aparece indicado o site da Internet com os resultados do survey: http://www.ucm.es/info/isa/books. Ver também Mommsen (2000, p. 364).

3 Ver a nova edição brasileira pela Companhia das Letras, 2004, comemorativa do centenário da primeira edição em 1904-1905 (Weber, 2004).

4 Com a assistência de Melchior Palyi, antigo aluno de Weber.

5 Palavra que por sinal aparece, é só reparar, no subtítulo de um dos volumes da nova edição de $E S$ pela $M W G$, o vol. I/22 (Cf. adiante item 4).

$6 \mathrm{O}$ assunto será retomado no item 4 deste artigo.

7 O artigo de Schluchter, revisado depois de discutido no âmbito do projeto $M W G$, está publicado em Schluchter (1988).

8 Adiante veremos que, em sua novíssima edição alemã deste início de século, ES aparece, não composta de duas partes, mas decomposta em duas partes.

9 Possuo um exemplar da $3^{a}$ edição, herança do Prof. Cândido Procopio Ferreira de Camargo.

10 Johannes Winckelmann (1919-1985), sociólogo e jurista, foi professor da Universidade de Munique. Era um weberiano de coração. Sentia orgulho, costumava dizer, em se ver als Scbüler ("como um discípulo") de Weber. Tendo já se destacado como organizador de uma nova edição, em 1951, da coletânea dos escritos de Weber sobre metodologia científica - Gesammelte Aufsätze zur Wissenschaftslebre (cf. WL) - a partir daí acabou dedicando o resto de seus dias ao trabalho de curador, divulgador e promoter da obra do venerado mestre.

11 Foi só a partir de 1964, data da segunda edição mexicana de Economia y sociedad (EyS) - a primeira edição é de 1944, pioneira entre todas as traduções , que o texto desse prefácio de Winckelmann ficou mais acessível aos leitores brasileiros em espanhol. Em português, só em 1991, na tradução brasileira da Editora Universidade de Brasília.

12 O caso mais flagrante de recorta-e-cola é o da "Sociologia do Estado" [Staatssoziologie], que corresponde à Seção 8 do Cap. IX ("Sociologia da dominação") da Segunda Parte de Economia e socie- 
dade no formato padrão produzido por Winckelmann (cf. EeS II, pp. 517-580; $W u G$, pp. 815-868).

13 Haja vista o ensaio "Uber einige Kategorien der verstehenden Soziologie" ["Sobre algumas categorias da Sociologia compreensiva"], publicado em 1913 na revista Logos (em WL, pp. 427-474).

14 Abaixo do título Grundriss der Sozialökonomik, trazia o nome de Max Weber como organizador (cf. $G d S, 1914)$.

15 Como se pode ver, dificuldades e divergências na tradução sempre haverá.

16 Em $M W G$ II/ 8, pp. 449-450.

17 Abandonou-o para se dedicar a outro projeto, igualmente vasto, de Sociologia da Religião, denominado "A ética econômica das religiões mundiais".

\section{BIBLIOGRAFIA}

CAMIC, Charles; GORSKI, Philip S. \& TRUBEK, David M. (2005), Max Weber's Economy and society: a critical companion. Stanford, Stanford University Press.

CHAZEL, François \& GROSSEIN, Jean-Pierre. (2005), "Présentation: lire Max Weber". Revue Française de Sociologie, 46 (4): 641-652, , octobredécembre.

[E\&S] WEBER, Max. (1968), Economy and society: an outline of interpretive sociology. Nova York, Bedminster Press, 2 vols.

[EeS] - (1991), Economia e sociedade: fundamentos da sociologia compreensiva. Brasília, Editora Universidade de Brasília, vol. I.

[EyS] _. ([1944] 1964), Economía y sociedad: esbozo de sociología comprensiva. México, Fondo de Cultura Económica, 2 vols.

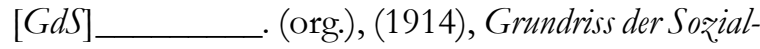
ökonomik. Tübingen, Mohr [Siebeck], vol. I.

GROSSEIN, Jean-Pierre (2005). De l'interprétation de quelques concepts wébériens. Revue Française de Sociologie, 46-4, octobre-décembre: pp. 685721.

KÄSLER, Dirk. (1988), Max Weber: an introduction to his life and work. Chicago, The University of Chicago Press.

LICHTBLAU, Klaus. (2003), "Die beiden Soziologien von Max Weber". Max Weber Studies, 3 (2): 233-238.
MOMMSEN, Wolfgang J. (2000), “Max Weber's 'grand sociology': the origins and composition of 'Wirtschaft und Gesellschaft. Soziologie"'. History and Theory, 39 (3): 364-383 [reproduzido em Charles Camic, Philip S. Gorski e David M. Truber (orgs.). (2005), Max Weber's Economy and society: a critical companion, Stanford, Stanford University Press, pp. 70-97.

PIERUCCI, Antônio Flávio. (2003), O desencantamento do mundo: todos os passos do conceito em Max Weber. São Paulo, Editora 34.

POGGI, Gianfranco. (1986), "Max Weber: a monumental edition in the making". British Journal of Sociology, 37 (2): 297-303, June.

SCHLUCHTER, Wolfgang. (1988), "Wirtschaft und Gesellschaft': Das Ende eines Mythos", in $\longrightarrow$ Religion und Lebensführung, Frankfurt, Suhrkamp, vol. 2, pp. 597-634 [trad. ingl.: " Economy and society': the end of a myth", Rationalism, religion, and domination: a Weberian perspective, Berkeley, University of California Press, pp. 433-463, 1989]. (1998), "Max Webers Beitrag zum 'Grundriss der Sozialökonomik': Editionsprobleme und Editionsstrategien”. Kölner Zeitschrift für Soziologie und Sozialpsychologie, 50 (2): pp. 327-343.

TENBRUCK, Friedrich H. (1975), "Das Werk Max Webers". Kölner Zeitschrift für Soziologie und Sozialpsychologie, 27 (4): 663-702, Dec. [Trad. ingl.: "The problem of thematic unity in the work of Max Weber". British Journal of Sociology, 31 (3): 313-351, Sept., 1980].

TENBRUCK, Friedrich H. (1977), "Abschied von Wirtschaft und Gesellschaft". Zeitschrift für die gesamte Staatswissenschaft, 133: 703-736.

[WL] WEBER, Max. ([1922] 1988), Gesammelte Aufsätze zur Wissenschaftslebre. Tübingen, Mohr [Siebeck].

$[W u G] \longrightarrow$ ([1922] 1985), Wirtschaft und Gesellschaft: Grundriss der verstehenden Soziologie (Reimpressão da 5 ed. revista por Johannes Winckelmann). Tübingen, Mohr [Siebeck].

WINCKELMANN, Johannes. (1986), Max Webers binterlassenes Hauptwerk: Entstebung und gedanklicher Aufbau. Tübingen, Mohr [Siebeck]. 


\section{ECONOMLA E SOCIEDADE: \\ ÚLTIMOS ACHADOS SOBRE A "GRANDE OBRA" DE MAX WEBER}

\section{Antônio Flávio Pierucci}

Palavras-chave: Max Weber; Obra principal; Economia e Sociedade; Nova composição

Com a nova edição de Economia e sociedade no quadro da Max Weber-Gesamtausgabe $(M W G)$, repuseram-se algumas questões objetivas que remontam aos inícios de uma longa história de controvérsias. A principal delas é se os textos juntados debaixo desse título formam de fato uma obra unitária, melhor dizendo, coerentemente unitária. Como corolário inevitável dessa dúvida crítica, recolocou-se também a questão de saber se uma obra com tal composição de textos, à base de originais com datas tão diferentes e espaçadas umas das outras, pode continuar a ser vista como "a obra principal" de Weber.

\section{ECONOMY AND SOCIETY: THE LAST FINDINGS ABOUT THE "GREAT WORK" OF MAX WEBER}

\section{Antônio Flávio Pierucci}

Keywords: Max Weber; Major work; Economy and Society; New composition

With the new issue of Economy and society in the listings of Max Weber-Gesamtausgabe ( $M W G$ ), some objective questions dating back to its controversial beginnings have arisen, the principal one being whether the essays gathered under this title form in fact a unitary work, that is, a coherently unitary one. As an inevitable corollary of such critical uncertainty, it has been equally questioned if a work with this composition of texts, based on such differently dated and spaced originals, can still be seen as "the main work" of Weber.

\section{ÉCONOMIE ET SOCIETÉ: \\ DERNIÈRES DÉCOUVERTES SUR LA “GRANDE OEUVRE" DE MAX WEBER}

\section{Antônio Flávio Pierucci}

Mots-clés: Max Weber; Oeuvre capitale; Économie et société; Nouvelle composition

Avec la nouvelle édition de Économie et société dans le cadre de la Max WeberGesamtausgabe $(M W G)$, certaines questions objectives, qui remontent aux débuts d'une longue histoire de controverses, se sont à nouveau posées. La principale d'entre elles consiste à savoir si les textes réunis sous ce titre forment, de fait, une œuvre unitaire, ou mieux encore, une œuvre d'une cohérence unitaire. Comme corollaire inévitable à ce doute critique, la question s'est également posée de savoir si une œuvre avec une telle composition de textes, à base d'originaux dont les dates sont aussi différentes qu'espacées les unes des autres, peut continuer à être considéré comme "l'œuvre principale" de Weber. 